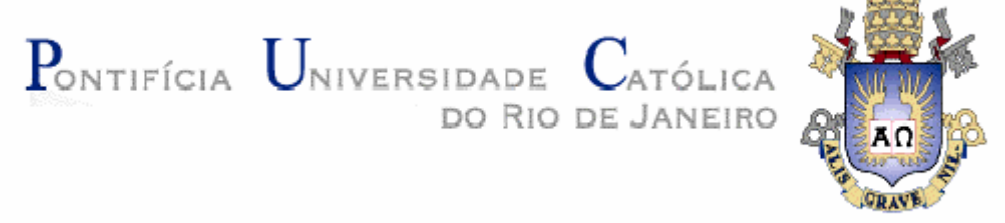

Arheta Ferreira de Andrade

\title{
Por uma Estética de Respeito às Diferenças: \\ Projeto Pátio da Fantasia
}

\section{Dissertação de Mestrado}

Dissertação apresentada como requisito parcial para obtenção do grau de Mestre pelo Programa de Pos-graduação em Educação do Departamento de Educação da PUC-Rio.

Orientador: Prof. Leandro Konder 


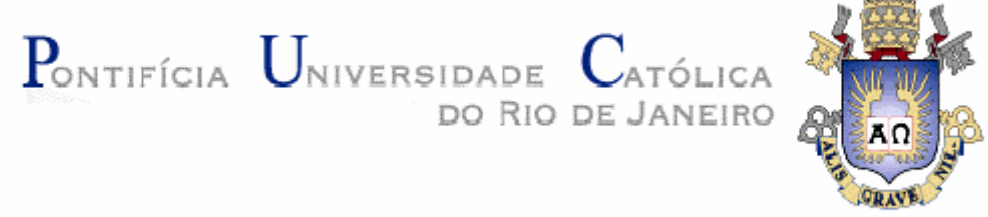

Arheta Ferreira de Andrade

\section{Por uma Estética de Respeito às Diferenças: \\ Projeto Pátio da Fantasia}

Tese apresentada como requisito parcial para obtenção do título de Doutor pelo Programa de Pós-Graduação em Educação do Departamento de Educação do Centro de Teologia e Ciências Humanas da PUC-Rio. Aprovada pela Comissão Examinadora abaixo assinada.

Prof. Leandro Konder Orientador

Departamento de Educação - PUC-Rio

Prof $^{a}$. Ana Waleska P. C. Mendonça Departamento de Educação - PUC-Rio

Prof $^{a}$. Rosana Glat UERJ

Prof. Paulo Fernando C. de Andrade Coordenador Setorial do Centro de Teologia e Ciências Humanas

Rio de Janeiro, 14 de abril de 2008 
Todos os direitos reservados. É proibida a reprodução total ou parcial do trabalho sem autorização da universidade, da autora e do orientador.

\section{Arheta Ferreira de Andrade}

Estudou canto lírico no Conservatório Pernambucano de Música (1994 - 2000). Cursou Licenciatura em Educação Artística / Habilitação em Artes Cênicas na Universidade Federal de Pernambuco (2002), sendo bolsista de extensão universitária no Projeto Pátio da Fantasia. Especializou-se em Ensino de Arte / Habilitação em Artes Cênicas pela mesma Universidade (2005). Tem experiência como atriz e cantora em espetáculos teatrais e como professora de teatro em escolas públicas e particulares e em ONGs. Atualmente trabalha no Instituto de Arte TEAR (RJ) como Arte-educadora e Coordenadora de Projetos Sociais.

Ficha Catalográfica

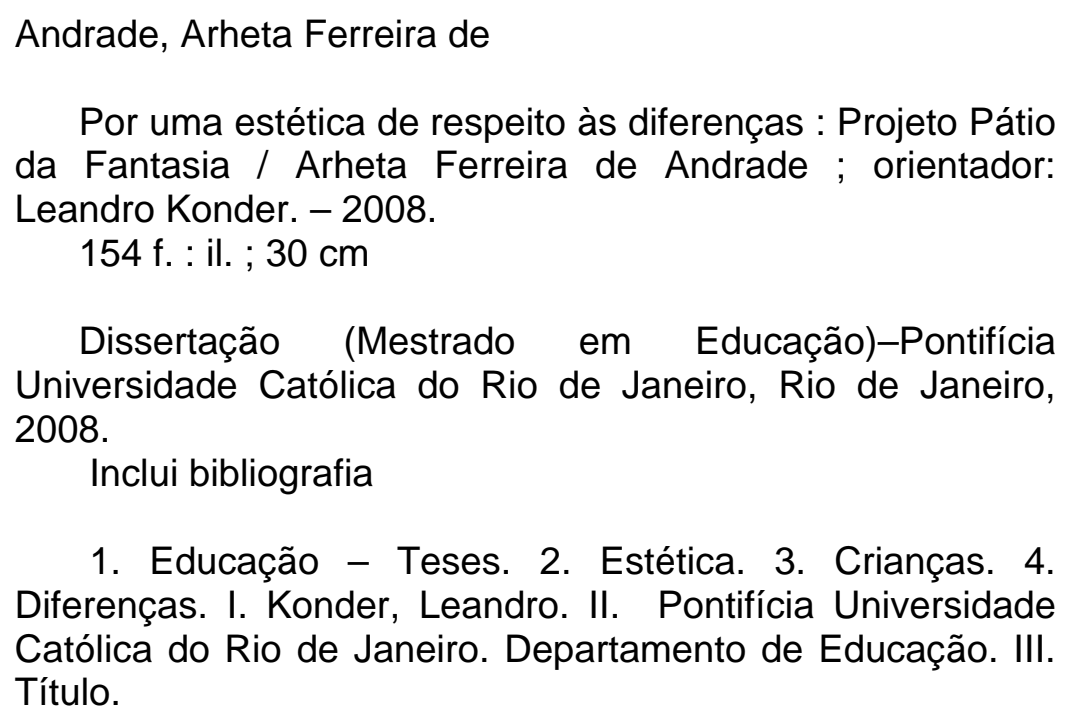
da Fantasia / Arheta Ferreira de Andrade ; orientador: Leandro Konder. - 2008.

1. Educação - Teses. 2. Estética. 3. Crianças. 4. Diferenças. I. Konder, Leandro. II. Pontifícia Universidade Católica do Rio de Janeiro. Departamento de Educação. III. Título. 
À minha mãe, que me mostra, desde quando eu era pequena, que como o fogo, a gente às vezes precisa abrir clarões dentro das dificuldades que aparecem em nossas vidas. Sem sua força e coragem de fogo eu nunca poderia ser o que sou.

Ao meu pai por me mostrar o quanto somos feitos de sonhos.

À minha tia Lécia e ao meu tio Eduardo por fincarem seus pés ao meu lado sempre que precisei de ajuda.

A Marco Camarotti (in memorian) que, como meu professor, plantou em minha alma a beleza das diferenças, a profundidade do encontro e a esperança de um mundo melhor.

A José, meu companheiro, por abraçar a minha vida com seu amor e carinho.

Às minhas irmãs e ao meu irmão por encher minha vida de felicidade. Às minhas sobrinhas e sobrinhos por, sempre, resgatar em meu coração a esperança. 


\section{Agradecimentos}

Ao meu companheiro José pela ajuda constante na construção deste trabalho e pelas horas dedicando atenção às minhas dúvidas e incertezas.

À minha família carioca, em especial à minha sogra e ao meu sogro, pelo carinho, disponibilidade e dedicação. Obrigada por fazerem me sentir como uma filha.

Ao Professor Leandro pela serenidade de sua atenção e pelo respeito às minhas idéias. Desse encontro levarei ensinamentos que extrapolam os limites da academia.

À Professora Vera Maria Candau pela validade que deu às minhas inquietações pessoais e profissionais e por abrir as portas de seu Grupo de Pesquisa - GECEC para que eu pudesse entrar e aprender sobre as diferenças.

À Professora Rosália Duarte pelo carinho com que me sempre me recebeu e recebe.

A todos os amigos e amigas do Instituto de Arte TEAR pelo carinho e acolhida.

Aos amigos e amigas do GECEC da PUC-Rio, com quem dividi os processos, às vezes sofridos, de aprendizagens intelectuais.

À amiga Vanessa Portella, também companheira da turma 2006 de mestrado da PUC-Rio. Obrigada pela dedicação e carinho.

À amiga Vrinha pelo carinho e companheirismo nas horas de sufoco.

Aos meus informantes, que tanto me ajudaram na construção desta pesquisa. 


\section{Resumo}

Andrade, Arheta Ferreira de; Konder, Leandro. Por uma estética de respeito às diferenças: Projeto Pátio da Fantasia. Rio de Janeiro, 2008. 154p. Dissertação de Mestrado - Departamento de Educação, Pontifícia Universidade Católica do Rio de Janeiro.

Uma experiência realizada nos anos entre 1998 e 2002, que desenvolveu atividades teatrais para e com crianças, priorizando aquelas que têm alguma deficiência, fomentou reflexões que motivaram esta pesquisa. A experiência em questão intitulava-se "Projeto Pátio da Fantasia”, e foi realizada no Curso de Educação Artística / Habilitação em Artes Cênicas do Departamento de Teoria da Arte e Expressão Artística da Universidade Federal de Pernambuco - UFPE. O objetivo desta pesquisa foi entender como o "Projeto Pátio da Fantasia” criou e desenvolveu atividades cênicas que levassem em consideração as diferenças das crianças e especificamente das crianças com deficiência. Para tanto, se apoiou nas contribuições de alguns estudos da Sociologia da Infância; Estética e Diferença. A pesquisa apresentada baseou-se nos pressupostos da abordagem qualitativa, tendo como instrumentos: entrevistas semi-estruturadas (com ex-integrantes do Projeto estudado e com representantes das instituições nas quais o objeto em questão realizou suas atividades) e material documental. As conclusões obtidas ressaltaram a importância e a necessidade do reconhecimento das diferenças das crianças com deficiência no campo da Produção Teatral para a Infância.

\section{Palavras-chave:}

Estética; Crianças; Diferenças. 


\section{Abstract}

Andrade, Arheta Ferreira de; Konder, Leandro (Advisor). To an esthetics of respect to differences: Project Pátio da Fantasia. Rio de Janeiro, 2008. 154p. MSc. Dissertation - Departamento de Educação, Pontifícia Universidade Católica do Rio de Janeiro.

This research was motivated by an experience realized between 1998 and 2002 that has developed theatrical scenes to and with children, particularly to children with disabilities. The experience entitled "Projeto Pátio da Fantasia" (Fantasy Patio Project) was developed in the Course of Artistic Education/ Department of Art Theory and Artistical Expression of Federal University of Pernambuco - UFPE. The objective of this research was to understand how this Project created and developed scenical activities that considered children's differences, especially to children whit disabilities. Contributions from studies on Sociology of Childhood, Esthetic and Difference were considered in this study. Semi-structured interviews were used based on a qualitative approach. These interviews were carried out with ex-components of the Project and with representatives from institutions where the Project developed their activities. The conclusions stress the importance and the need to recognize the differences of children with disability in the field of Theatral Production to Childhood.

\section{Keywords}

Esthetics; Children; Differences. 


\section{Sumário}

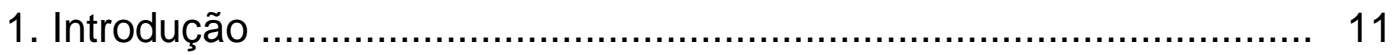

2. Referências Teóricas ............................................................ 17

2.1. Sobre Estética .............................................................. 19

2.2. Quando a diferença a ser criança ............................................ 25

2.3. Quando a criança é diferente .................................................. 31

2.4. Ensino de arte, produção de arte e respeito às diferenças ............. 44

2.5. A Linguagem no Teatro Infantil ...................................... 53

3. História do Projeto Pátio da Fantasia ...................................... 59

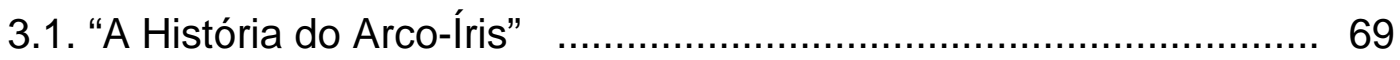

3.2. "O Retorno dos Piratas" ................................................. 72

3.3. "A Fazenda Encantada" ..................................................... 75

3.4. "O Carro Aloprado" ............................................................... 77

4. Procedimentos Metodológicos ................................................ 84

5. Estética e Diferença no Projeto Pátio da Fantasia ......................... 95

5.1. Ideais Poéticos ............................................................... 97

5.1.1. O compromisso com a estética infantil ............................... 98

5.1.2. O respeito às diferenças das crianças com deficiência .............. 104

5.2. Normas Poéticas .................................................................. 115

5.2.1. "A História do Arco-Íris" ......................................................... 119

5.2.2. "O Retorno dos Piratas" .................................................... 122

5.2.3. "A Fazenda Encantada"................................................ 124

5.2.4. "O Carro Aloprado" .................................................... 129

6. Considerações Finais .................................................... 135

7. Referencias bibliográficas ............................................... 143

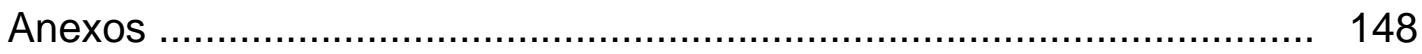




\section{Lista de figuras e fotografias}

Figura 1: Esquema explicativo da estrutura organizacional do Projeto Pátio da Fantasia

Figura 2: Esquema explicativo das subdivisões da categoria de análise

Foto 1: Apresentação da "História do Arco-Íris" num seminário dos projetos de extensão da Pró-Reitoria de Extensão da Universidade Federal de Pernambuco

Foto 2: Uma das cenas do quadro teatral "A História do Arco-Íris"

Fotos 3 e 4: Apresentação do quadro "O Retorno dos Piratas" na Pediatria do Hospital das Clínicas de Pernambuco

Foto 5: Representação da personagem de um dos quadros teatrais do Projeto Pátio da Fantasia

Foto 6: Primeira apresentação do "Carro Aloprado" na Escola Especial Ulisses Pernambucano

Foto 7: Oficina realizada na Escola Ulisses Pernambucano com alguns profissionais da Educação Especial do Estado de PE e representantes de comunidades de surdos

Fotos 8: Idem foto 7 
“... Eu sempre sonho que uma coisa gera, nunca nada está morto. O que não parece vivo, aduba. O que parece estático, espera”. 